\title{
MVA-FCU1 TG4023
}

National Cancer Institute

\section{Source}

National Cancer Institute. MVA-FCU1 T G4023. NCI Thesaurus. Code C88279.

A cancer vaccine comprised of a recombinant modified vaccinia Ankara (MVA) viral vector encoding the suicide gene FCU1 with potential antineoplastic activity. FCU1 is a bifunctional yeast cytosine deaminase (CD) / uracil phosphoribosyltransferase (UPRT) fusion gene. Upon intratumoral administration, MVA-FCU1T G4023 enters tumor cells where FCU1 is expressed. Subsequently, the noncytotoxic prodrug 5-fluorocytosine (5FC) is administered systemically and is deaminated by CD in FCU1- transduced tumor cells into 5-fluorouracil (5-FU), which is then directly metabolized to 5-fluoro-uridine monophosphate (5-FUMP) by UPRT; 5-FUMP may then be further transformed to 5fluoro-deoxyuridine monophosphate (5-FdUMP), an irreversible inhibitor of thymidylate synthase and, so, DNA synthesis through deprivation of deoxythymidine triphosphate (dTTP). 5-FU and its active metabolites may then selectively kill tumor cells, avoiding toxicity in nonmalignant cells. The MVA viral vector, derived from the replicationcompetent strain Ankara, is a highly attenuated, replication-defective vaccinia strain incapable of virion assembly. 